\title{
PERAN HASHTAG \#INDONESIABUCKETLIST PADA KONTEN REGRAM @INDTRAVEL DALAM UPAYA CUSTOMER ENGAGEMENT MARKETING DI MASA PANDEMI COVID-19
}

\author{
Ahmadintya Anggit Hanggraito \\ Politeknik Negeri Banyuwangi \\ Email: ahmadintya.anggithanggraito@poliwangi.ac.id \\ Setya Mukti Mahanani \\ Universitas Gadjah Mada \\ Email: smahananii@mail.ugm.ac.id \\ Noer Ayufika Nulul \\ Universitas Gadjah Mada \\ Email: noer.ayufika.nulul@mail.ugm.ac.id
}

\begin{abstract}
Instagram becomes prominent social media that connect online communities to tourism destination although Covid-19 occurs. This study aims to explore the role of regram contents which are followed with \#IndonesiaBucketList in Ministry of Tourism and Creative Economy of Indonesia Instagram official account, @indtravel. Data collected was the posts including photos, captions, comments, and likes, uploaded during the period of social restriction (PSBB) to emergency restriction (PPKM) for Java and Bali in third quarter of 2021. In particular, the present study examines customer engangement marketing model of @indtravel marketing practices in a time of crisis. Content analysis was employed in this qualitative descriptive study by identifying the regram contents posted with hashtag \#IndonesiaBucketList. The results reveal that natural attraction category was the primary theme of the contents along with the most mentioned provinces, such as East Nusa Tenggara, Bali, Central Java, and East Java. It is also consistent that customer engagement cycle of @indtravel suggest customer engangement marketing practice is dealing with tourism crisis during Covid-19 pandemic.
\end{abstract}

Keywords: Instagram, Social Media, Regram, Hashtag, Customer Engagement Marketing, Tourism Crisis. 


\section{Pendahuluan}

Indonesia merupakan salah satu negara yang sebagian besar warganya menggunakan internet dalam kegiatan sehari-harinya. Hingga kuartal II, pengguna internet mencapai 196,7 juta atau $73,7 \%$ dari populasi Indonesia di tahun 2020 (Jatmiko, 2020). Di samping itu, pengguna media sosial sekitar 48\% dari populasi di Indonesia (Wearesocial, 2019). Pertumbuhan pengguna media sosial menciptakan fenomena dalam promosi dan kesadaran akan keberadaan destinasi pariwisata (Hanan \& Putit, 2013). Dengan kata lain, media sosial ikut membantu menunjukkan minat dari pasar yang dipromosikan melalui konten unggahan yang terkait destinasi pariwisata. Secara global, media sosial dengan pertumbuhan positif tertinggi hingga 4,4\% pada tahun 2019 adalah instagram (Kemp, 2019). Instagram dapat berkontribusi sebagai media pemasaran destinasi wisata Indonesia. Salah satu akun Instagram yang dikelola secara resmi oleh pemerintah adalah @indtravel. Berbagai konten dari @indtravel berasal dari hasil regram dari berbagai unggahan pengalaman follower serta caption kalimat yang menginspirasi audiens untuk berkunjung ke destinasi yang dipromosikan (Kusuma dkk., 2020). Oleh karena itu, @indtravel berpotensi mengoptimalkan customer engagement marketing dari destinasi wisata Indonesia di era 4.0 .

Tabel 1. Akun Instagram resmi negara Asia Tenggara

\begin{tabular}{llcccc}
\hline Negara & Akun Instagram & $\begin{array}{c}\text { Jumlah } \\
\text { pengikut } \\
\text { (s.d. } \\
\text { Oktober } \\
\text { 2021, } \\
\text { dalam } \\
\text { ribu) }\end{array}$ & $\begin{array}{c}\text { Total } \\
\text { Unggahan }\end{array}$ & $\begin{array}{c}\text { Rasio } \\
\text { unggahan }\end{array}$ & $\begin{array}{c}\text { Kunjungan } \\
\text { Wisatawan } \\
\text { (s.d. 2018, } \\
\text { dalam ribu) }\end{array}$ \\
\hline Malaysia & @malaysia.truly.asia & 152 & 2696 & 56,38 & 25.800 \\
Singapura & @visit_singapore & 480 & 1292 & 371,52 & 18.500 \\
Thailand & $@$ @tourismthailand & 145 & 2419 & 59,94 & 38.300 \\
Indonesia & @indtravel & 680 & 3078 & 220,92 & 15.806 \\
$352 \quad$ JUMPA Volume 8, Nomor 2, Januari 2022 & & & \\
\hline
\end{tabular}


Peran Hashtag \#Indonesiabucketlist pada Konten Regram @Indtravel...

\begin{tabular}{llcccc} 
Myanmar & $@ m y a n m a r t o u r i s m$ & 39 & 940 & 41,49 & 3.600 \\
Brunei & $@$ brunei.tourism & 14.8 & 625 & 23,68 & 1.400 \\
\hline
\end{tabular}

Sumber: Data diolah Peneliti, 2021

Tabel 1 menunjukkan bahwa, @indtravel memiliki rasio unggahan sebanyak 3078 konten dengan jumlah follower 220,92 kali lipatnya. Apabila dibandingkan dengan jumlah wisatawan di kawasan asia tenggara, Indonesia masih jauh dibandingkan Malaysia $(56,38)$ maupun Thailand $(59,94)$ yang memiliki rasio pengikut instagram lebih kecil. Dalam situasi pandemi Covid-19, @indtravel berpeluang meningkatkan customer engagement marketing dari destinasi wisata Indonesia. Adanya customer engagement marketing mendorong keterlibatan pelanggan secara langsung dan berkelanjutan agar membentuk brand conversations, brand experiences, dan brand community (Kotler dkk., 2018). Dalam proses customer engagement marketing, pengalaman dan cerita yang dibagi di Instagram akan mengoptimalkan brand dari destinasi pariwisata di masa pandemi Covid-19.

Konsistensi @indtravel selama pandemi Covid-19 memberikan justifikasi mengenai adanya strategi pemulihan pariwisata. Pemulihan pariwisata negara berkembang menghadapi banyak tantangan karena sumber daya manusia dan keuangan yang terbatas, struktur tata kelola yang tidak jelas, dan kurangnya perencanaan pariwisata (Novelli dkk., 2012; Shao dkk., 2021). Faktanya, Pemerintah Indonesia tidak menghentikan kegiatan pemasaran untuk mempromosikan pariwisata Indonesia ke pasar global (Chloridiany, 2021). Walaupun, pemerintah Indonesia sendiri ikut melaksanakan pembatasan wilayah demi mencegah laju penyebaran virus Covid-19. Dimana, pembatasan wilayah di Indonesia secara konstruktif dimulai dengan penerapan PSBB di Jakarta dimulai 10 april hingga 23 april 2020 (kompaspedia, 2021). Oleh karena itu, upaya customer engagement marketing melalui @indtravel dapat menjadi salah satu strategi pemerintah di masa krisis. 
Salah satu materi penting dalam konten regram @indtravel di masa krisis tertuju pada penggunaan hashtag \#IndonesiaBucketList. Hashtag/tanda pagar biasanya untuk mengelompokkan pesan pada media sosial agar mudah ditemukan, serta sebagai pembentuk trending topic atas apa yang sedang banyak orang jadikan hashtag (Permatasari dan Trijayanto, 2017). 5408 konten instagram ber-hashtag \#IndonesiaBucketList yang terunggah hingga akhir triwulan III tahun 2021 menunjukkan adanya upaya customer engagement marketing melalui media sosial tetap berjalan di masa krisis. Berdasarkan latar belakang tersebut, inisiasi @indtravel dalam setiap konten ber-hashtag \#IndonesiaBucketList memiliki karakteristik yang spesifik. Tujuan penelitian ini mengeksplorasi peran hashtag \#IndonesiaBucketList dalam konten regram @indtravel selama pandemi covid-19. Secara khusus, model customer engagement marketing dari konten regram @indtravel untuk menjalankan promosi di masa krisis.

\section{Kerangka Pikir}

Wisatawan menganggap media sosial sebagai alat penting untuk melestarikan dan mengekspresikan pengalaman perjalanan mereka, kemudian membagikannya dalam opini tertulis, gambar, atau video (Benedek, 2018). Media sosial sebagai tujuan pemasaran didefinisikan sebagai platform seseorang untuk membangun jaringan dan berbagi informasi dan/atau sentimen (Kaplan \& Haenlein, 2010). Regram merupakan istilah unggah ulang konten foto maupun video pada Instagram bertujuan untuk penyebaran informasi (Kusuma dkk., 2020). Di sisi lain, storytelling sebagai sebuah narasi pengubah yang menghubungkan identitas dan filosofi dalam pemasaran, dimana kemudian menghasilkan aktivitas dan produk (Josef dkk., 2014). Sehingga, deskripsi gambar dan storytelling dapat menjadi material penting dari konten promosi terkait destinasi wisata.

Dalam hal ini, promosi menjadi bagian penting dalam proses branding dari destinasi pariwisata. Branding bertujuan mengidentifikasi dan membedakan tujuan 
melalui citra positif yang dibangun dengan memilih campuran elemen merek (Cai, 2002). Tourism destination branding adalah proses pembangunan keunikan yang dimiliki oleh destinasi pariwisata dan mengkomunikasikannya kepada wisatawan atau investor dengan menggunakan nama, tagline, simbol, desain atau kombinasi dari media tersebut untuk menciptakan image positif (Nafees \& Harish, 2010). Oleh karena itu, Brand dari destinasi wisata dapat dianggap sebagai sebuah produk tangible dan intangible yang mampu menarik wisatawan. Sehingga, promosi melalui konten regram @indtravel berperan penting dalam upaya customer engagement marketing dari destinasi wisata di masa krisis pandemi Covid-19.

Customer engagement dapat didefinisikan sebagai aktivitas pemasaran yang berorientasi pada perilaku dan psikologis pelanggan (So dkk., 2014). Adanya pertumbuhan pemakaian internet dan media sosial tersebut, interaksi antara pelanggan-pelanggan dan pelanggan perusahaan menjadi mudah dilakukan (Evans, 2010). Oleh karena itu, pemerintah dapat mengoptimalkan customer engagement marketing melalui efisiensi media sosial @indtravel selama pandemi Covid-19. Customer engagement marketing diharapkan mampu membangun ikatan positif dari destinasi wisata dengan wisatawan secara global. Dalam proses customer engagement yang berkelanjutan terdapat siklus penting dalam membangun ikatan positif tersebut. Siklus Customer engagement menurut Sashi (2012), yakni:

1. Koneksi. Pembentukan rasionalitas dengan ikatan emosional, dibutuhkan brand dan pelanggan (followers) yang berhubungan satu sama lain.

2. Interaction. Ketika terhubung, pelanggan (followers) dapat berinteraksi dengan brand dan juga dengan pelanggan (followers) lainnya.

3. Satisfaction. Ketika interaksi menghasilkan kepuasan, maka pelanggan (followers) akan tetap terhubung dan terus berinteraksi satu sama lain agar terjadi engagement.

4. Retention. Ingatan Customer tentang sebuah brand dapat berasal dari keseluruhan kepuasan dari waktu ke waktu atau emosi positif yang sangat tinggi. 
5. Commitment. Pertama, Calculative commitment lebih rasional dan berasal dari kurangnya pilihan. Sehingga, muncul kedekatan dengan brand. Kedua, affective commitment berasal dari rasa emosionalitas dan kepercayaan. Sehingga, muncul timbal balik dalam sebuah hubungan.

6. Advocacy. Advokasi adalah sejauh mana pelanggan mendukung brand dan menyebarkan word of mouth (WOM) positif. Kemudian, mempromosikan brand kepada followers baru dan mempertahankan brand dari kritik orang lain.

7. Engagement: Saat pengguna media sosial senang berbagi kesenangan, loyalitas mereka terlihat dengan cara interaksi di jejaring sosial. Hal ini akan menjadi anjuran berwisata ke destinasi. Customer engagement terjadi saat pelanggan (followers) mempunyai ikatan emosional yang kuat dalam pertukaran rasional dengan brand.

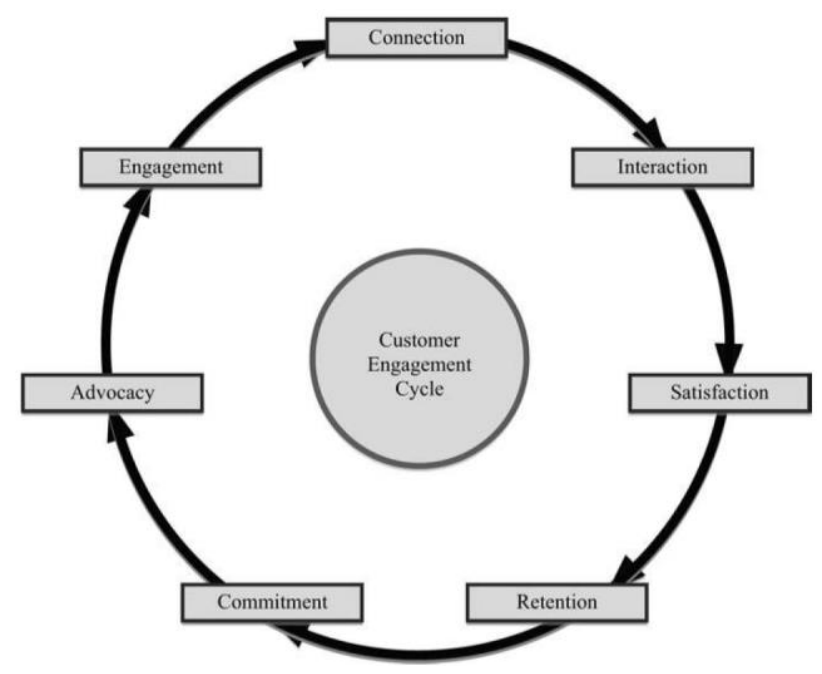

Gambar 1. Customer Engagement Cycle Sumber: (Data diolah peneliti, 2021)

Secara umum, pandemi Covid-19 telah menjadi bagian dari krisis kepariwisataan di Indonesia. Krisis pariwisata sendiri berkaitan dengan peristiwa kejahatan, teror, kerusuhan politik, bencana alam, epidemi dan kecelakaan (Glaesser, 2006). Pengelolaan krisis pariwisata membutuhkan tindakan sebelum, selama, dan 
setelah krisis (Sigala, 2020). Branding destinasi wisata melalui @indtravel dapat dianggap sebagai program dalam aksi pemulihan di masa krisis. Implikasi dari adanya intervensi pemerintah dapat dikonsepsian pengelola destinasi dan pembuat kebijakan pariwisata agar mereka terbantu dalam membuat keputusan yang tepat, membuat tolok ukur kebijakan mereka selama krisis, dan akhirnya menghasilkan ideide baru (Kuščer dkk., 2021). Upaya pemerintah melalui aktivitas regram @indtravel diharapkan dapat mengoptimalkan customer engagement marketing dari destinasi wisata di masa krisis.

\section{Metode Penelitian}

Penelitian ini menggunakan pendekatan kualitatif deskriptif dengan menerapkan metode analisis konten. Penelitian deskriptif difokuskan untuk membuat deskripsi secara sistematis dan akurat berdasarkan fakta-fakta tentang suatu objek tertentu (Suryana, 2010). Pendekatan penelitian kualitatif lebih holistik dan sering melibatkan kumpulan data yang kaya dari berbagai sumber untuk mendapatkan pemahaman yang lebih dalam dari masing-masing peserta, termasuk pendapat, perspektif, dan sikap mereka (Nassaji, 2015). Analisis konten memungkinkan seseorang untuk mengidentifikasi tema dan strategi, dan untuk mengekstrak makna, memberikan wawasan baru ke dalam fenomena tertentu dan menghasilkan generalisasi dan prediksi mengenai fenomena serupa (Krippendorff, 2004). Data dihimpun dari unggahan konten regram ber-hashtag \#IndonesiaBucketList pada masa PSBB hingga PPKM Jawa-Bali di triwulan ketiga tahun 2021, yakni 9 April s.d. 30 September 2021. Konten regram terkait pada gambar, video, komentar, dan like dengan hasil tabulasi pada Tabel 2. Analisis melalui program MAXQDA 2020 direpresentasikan dalam kategori tertentu. Pada tahap ini kode semantik yang saling memiliki kemiripan dikelompokkan dalam kategori kode yang sama. 587 kode yang ditemukan dalam konten regram @indtravel dikelompokkan dalam 56 kategori. Selanjutnya, setiap kategori dikhususkan dalam 7 dimensi kode tema. Kesimpulan 
dari hasil analisis, digeneralisasikan dalam beberapa pemaknaan strategi pemerintah dalam @indtravel terkait upaya customer engagement marketing dari destinasi wisata Indonesia di masa krisis.

\section{Hasil dan Pembahasan}

\section{Eksplorasi penggunaan akun instagram @indtravel}

@indtravel merupakan akun instagram milik Kementerian Pariwisata dan Ekonomi Kreatif (Kemenparekraf) yang berperan dalam regram konten pengguna instagram lain yang mengunggah pengalaman di destinasi wisata Indonesia. Intensitas unggahan konten yang di-regram oleh @indtravel berkisar antara 5 hingga 7 unggahan perminggu.

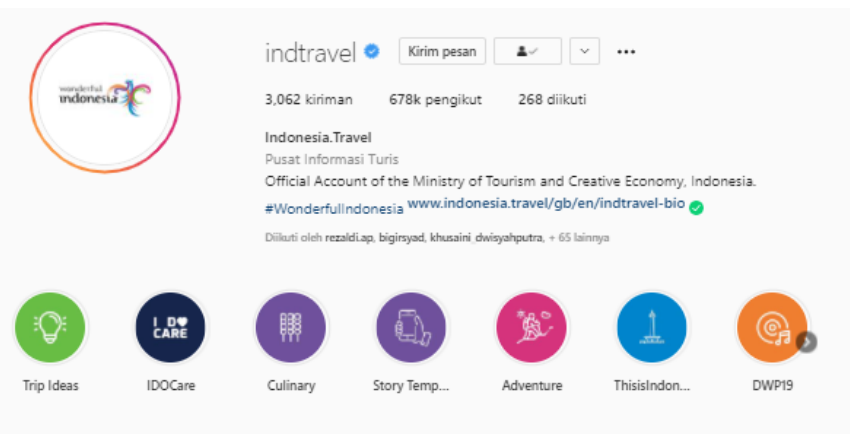

Gambar 2. Tampilan @indtravel Sumber: (Data diolah peneliti, 2021)

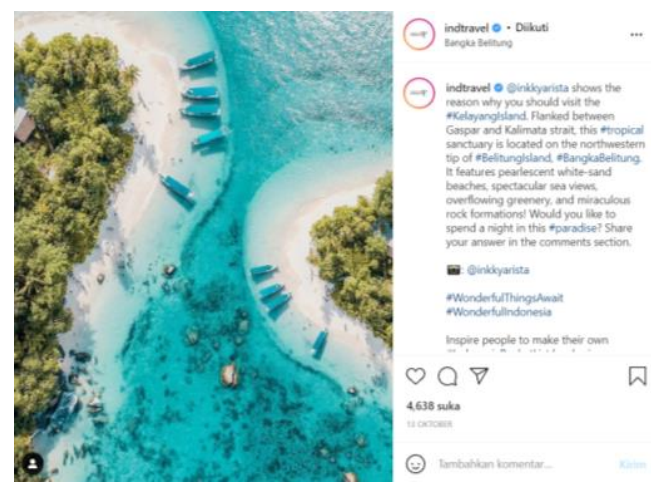

Gambar 3. contoh konten regram @indtravel Sumber: (Data diolah peneliti, 2021) 
Gambar 3. merupakan salah satu konten regram @indtravel ber-hashtag \#IndonesiaBucketList selama pembatasan wilayah. \#IndonesiaBucketList merupakan hashtag penting dalam memaknai berbagai konten regram. Pemberian hashtag dalam sebuah konten regram memudahkan dan membuka kesempatan para netizen untuk mendapatkan beberapa informasi berbeda dalam satu waktu (Mustofa, 2019). Dalam hal ini, netizen yang dimaksud adalah masyarakat penyimak berbagai konten @indtravel, baik sebagai follower atau non-follower.

Berikut eksplorasi terhadap konten regram dari @indtravel dengan hashtag \#IndonesiaBucketList. Terdapat pemaknaan terkait branding destinasi wisata Indonesia selama program PSBB hingga PPKM jawa-Bali di triwulan III tahun 2021. Berikut hasil analisis konten regram dari 139 gambar foto, 879.902 likes, dan 10954 komentar yang terhubung dengan hashtag \#indonesiabucketlist selama pembatasan wilayah,

Tabel 2. Identifikasi konten pada @indtravel

(awal PSBB s.d. PPKM Jawa Bali triwulan III tahun 2021)

\begin{tabular}{|l|l|l|l|}
\hline Tanggal & Lokasi & Like & comment \\
\hline April & \multicolumn{2}{l|}{} \\
\hline $\mathbf{9}$ & Taka Makasar & 4065 & 51 \\
\hline $\mathbf{1 0}$ & Pulo Cinta & 4713 & 64 \\
\hline $\mathbf{1 1}$ & Candi Borobudur & 7237 & 54 \\
\hline $\mathbf{1 2}$ & Danau Toba & 3591 & 31 \\
\hline $\mathbf{1 3}$ & Teluk Crystal & 5606 & 49 \\
\hline $\mathbf{1 4}$ & Goa Jomblang & 7206 & 74 \\
\hline $\mathbf{1 5}$ & Pasir Timbul & 6317 & 60 \\
\hline
\end{tabular}




\begin{tabular}{|l|l|l|l|}
\hline $\mathbf{1 6}$ & Batu Baginda & 6182 & 57 \\
\hline $\mathbf{1 7}$ & Candi Borobudur & 4943 & 38 \\
\hline $\mathbf{1 8}$ & Lembang & 6235 & 55 \\
\hline $\mathbf{2 0}$ & Bromo & 8861 & 109 \\
\hline $\mathbf{2 1}$ & Desa Bena & 3830 & 40 \\
\hline $\mathbf{2 2}$ & Pantai Tolanamon & 5564 & 52 \\
\hline $\mathbf{2 3}$ & Pulau Kanawa & 5001 & 67 \\
\hline $\mathbf{2 4}$ & Danau Toba & 4960 & 34 \\
\hline $\mathbf{2 5}$ & Kelabba Maja & 2979 & 20 \\
\hline $\mathbf{2 6}$ & Kawah Wurung & 3078 & 30 \\
\hline $\mathbf{2 7}$ & Situ Gunung & 5947 & 73 \\
\hline $\mathbf{2 9}$ & Pantai Watu Lumbung & 8770 & 88 \\
\hline $\mathbf{3 0}$ & Pantai Oetune & 3914 & 59 \\
\hline Total & & 108999 & 1105 \\
\hline $\mathbf{2}$ & & & \\
\hline
\end{tabular}

\begin{tabular}{|c|c|c|c|}
\hline \multicolumn{4}{|c|}{ Mei } \\
\hline 1 & Lubang Sewu Erorejo & 4445 & 45 \\
\hline 2 & Sawai & 6056 & 47 \\
\hline 3 & Kawah Ijen & 4443 & 35 \\
\hline 4 & Sesandan & 7253 & 61 \\
\hline 5 & Labuan Bajo & 5874 & 71 \\
\hline
\end{tabular}




\begin{tabular}{|c|c|c|c|}
\hline 7 & Kawah Putih & 5621 & 70 \\
\hline 8 & Candi Borobudur & 6536 & 71 \\
\hline 9 & Bukit Holbung & 3983 & 36 \\
\hline 10 & Bukit Sanghyangdora & 5348 & 63 \\
\hline 11 & Pulau Sombori & 4663 & 49 \\
\hline 12 & Bukit Cumbri & 2843 & 29 \\
\hline 13 & Masjid 99 Kubah & 4412 & 36 \\
\hline 14 & Misool & 7284 & 94 \\
\hline 15 & Desa Sidemen & 6807 & 48 \\
\hline 16 & Gunung Merbabu & 6192 & 89 \\
\hline 17 & Taman Nasional Kelimutu & 5348 & 43 \\
\hline 19 & Taman Nasional Komodo & 3455 & 45 \\
\hline 20 & Tabiang Takuruang & 3086 & 17 \\
\hline 21 & Lahangan Sweet & 3965 & 36 \\
\hline 22 & Gunung Bromo & 5676 & 50 \\
\hline 23 & Pantai Kelingking & 5272 & 45 \\
\hline 24 & Batu Termanu & 4187 & 66 \\
\hline 25 & Kampung Warna warni & 5351 & 63 \\
\hline 26 & Candi Borobudur & 8397 & 113 \\
\hline 27 & Pantai Padar & 25533 & 135 \\
\hline
\end{tabular}




\begin{tabular}{|l|l|l|l|}
\hline $\mathbf{2 8}$ & Tanjung Tinggi & 4630 & 83 \\
\hline $\mathbf{3 0}$ & Situ Cicerem & 12875 & 115 \\
\hline $\mathbf{3 1}$ & Tegallalang & 7629 & 89 \\
\hline Total & & 177164 & 1744 \\
\hline
\end{tabular}

\section{Juni}

\begin{tabular}{|l|l|l|l|}
\hline $\mathbf{1}$ & Kawah Ijen & 3721 & 57 \\
\hline $\mathbf{2}$ & One Tree Hill & 4684 & 46 \\
\hline $\mathbf{3}$ & Air Terjun Sekumpul & 4812 & 64 \\
\hline $\mathbf{4}$ & Pantai Mandorak & 4141 & 59 \\
\hline $\mathbf{5}$ & Tegallalang & 5707 & 58 \\
\hline $\mathbf{6}$ & De Djawatan & 7351 & 78 \\
\hline $\mathbf{7}$ & Wana Wisata Prabalintang & 8604 & 90 \\
\hline $\mathbf{8}$ & Pantai Kelingking & 5510 & 53 \\
\hline $\mathbf{9}$ & Pantai Oelangga & 5384 & 56 \\
\hline $\mathbf{1 0}$ & Poto Tano & 5915 & 84 \\
\hline $\mathbf{1 1}$ & Alahan Panjang & 4844 & 42 \\
\hline $\mathbf{1 2}$ & Taman Nasional Komodo & 6140 & 116 \\
\hline $\mathbf{1 3}$ & Pulau Pasumpahan & 8554 & 211 \\
\hline $\mathbf{1 4}$ & Danau Toba & 9217 & 150 \\
\hline $\mathbf{1 5}$ & Candi Sewu & 7573 & 125 \\
\hline
\end{tabular}




\begin{tabular}{|c|c|c|c|}
\hline 16 & Bukit Pergasingan & 6047 & 139 \\
\hline 17 & Taman Ujung Water Palace & 4357 & 68 \\
\hline 18 & Gardu Pandang Tieng & 4083 & 43 \\
\hline 19 & Bukit Kingkong & 6117 & 80 \\
\hline 20 & Air terjun Cikanteh & 5717 & 98 \\
\hline 21 & Dusun Butuh Kaliangkrik & 15281 & 207 \\
\hline 22 & Pantai Walakiri & 6089 & 66 \\
\hline 23 & Gua Kona Ba'u & 4169 & 73 \\
\hline 24 & Cemoro Lawang & 14344 & 195 \\
\hline 26 & Pantai Semeti & 8061 & 98 \\
\hline 27 & Situ Gunung & 9125 & 123 \\
\hline 28 & Raja Ampat & 6805 & 118 \\
\hline 29 & Pulau Padar & 7343 & 96 \\
\hline 30 & Pantai Pulau merah & 7686 & 106 \\
\hline Total & & 197381 & 2799 \\
\hline \multicolumn{4}{|l|}{ Juli } \\
\hline 1 & Bukit Cumbri & 5572 & 100 \\
\hline 2 & Sianok Anam Suku & 6023 & 136 \\
\hline 3 & Mount Bismo & 6217 & 79 \\
\hline 4 & Kapas Biru Waterfall & 6098 & 112 \\
\hline
\end{tabular}




\begin{tabular}{|l|l|l|l|}
\hline $\mathbf{5}$ & Merese Hill & 5385 & 107 \\
\hline $\mathbf{6}$ & Brown Canyon & 3626 & 93 \\
\hline $\mathbf{7}$ & Prambanan Temple & 5432 & 125 \\
\hline $\mathbf{8}$ & The Ulun Danu Beratan Temple & 4841 & 73 \\
\hline $\mathbf{1 0}$ & Komodo National Park & 5642 & 80 \\
\hline $\mathbf{1 1}$ & Bawah Reserve in Anambas & 5535 & 86 \\
\hline $\mathbf{1 2}$ & Raja Ampat & 7671 & 141 \\
\hline $\mathbf{1 3}$ & Broken Beach in Nusa Penida & 4959 & 75 \\
\hline $\mathbf{1 5}$ & Pulo Cinta & 8899 & 185 \\
\hline $\mathbf{1 6}$ & Paal Beach, Likupang & 3993 & 69 \\
\hline $\mathbf{1 7}$ & Wisata Geopark Ciletuh & 4214 & 54 \\
\hline $\mathbf{1 8}$ & Kelaba Madja, Sabu Island & 4968 & 63 \\
\hline $\mathbf{2 0}$ & Nusa Penida & 6969 & 69 \\
\hline $\mathbf{2 1}$ & Gunung Prau & 6661 & 74 \\
\hline $\mathbf{2 2}$ & Vihara Ksitigarbha Bodhisattva & 3105 & 38 \\
\hline $\mathbf{2 4}$ & Borobudur Temple & 5269 & 66 \\
\hline $\mathbf{2 6}$ & Sunrise Point Cukul & 3696 & 51 \\
\hline $\mathbf{2 7}$ & Mount Batur & 35 \\
\hline
\end{tabular}




\begin{tabular}{|c|c|c|c|}
\hline \multicolumn{2}{|c|}{ Total } & 126039 & 2017 \\
\hline \multicolumn{4}{|c|}{ Agustus } \\
\hline 1 & Mareje village Lombok & 5117 & 71 \\
\hline 3 & Derawan Island & 6738 & 86 \\
\hline 4 & Borobudur Temple & 7464 & 82 \\
\hline 6 & Selong Hill & 8180 & 75 \\
\hline 8 & Nyang-Nyang Beach & 8465 & 78 \\
\hline 9 & Waikelo Sawah Waterfall & 14656 & 242 \\
\hline 10 & De Djawatan & 6829 & 126 \\
\hline 11 & Ratenggaro & 5862 & 59 \\
\hline 14 & Mount Merbabu & 5093 & 49 \\
\hline 15 & Gobleg Hill Buleleng & 4190 & 38 \\
\hline 16 & Wurung Crater & 3967 & 56 \\
\hline 17 & Bollangi Hill & 4262 & 43 \\
\hline 18 & Borobudur Temple & 7690 & 78 \\
\hline 20 & Mata Jitu Waterfall & 4494 & 55 \\
\hline 21 & Tailana Island Aceh & 4076 & 28 \\
\hline 22 & Nihiwatu Beach & 5339 & 41 \\
\hline 23 & Karimun Jawa & 2869 & 25 \\
\hline 24 & Simargalung Ombun hill & 4951 & 74 \\
\hline
\end{tabular}




\begin{tabular}{|l|l|l|l|}
\hline $\mathbf{2 7}$ & Menjangan Island & 3939 & 50 \\
\hline $\mathbf{2 8}$ & Sunrise Point Cukul & 5087 & 50 \\
\hline $\mathbf{2 9}$ & Tanarara - Matawai La Pau & 8298 & 110 \\
\hline $\mathbf{3 1}$ & Labuan Bajo & 7633 & 118 \\
\hline Total & & 135199 & 1634 \\
\hline
\end{tabular}

\section{September}

\begin{tabular}{|l|l|l|l|}
\hline $\mathbf{1}$ & Kelingking Beach & 22474 & 71 \\
\hline $\mathbf{2}$ & Taman Labirin Coban Rondo & 8746 & 155 \\
\hline $\mathbf{4}$ & Situ Gunung Tourist Park & 6014 & 59 \\
\hline $\mathbf{8}$ & Tumpak Sewu Waterfall & 7541 & 89 \\
\hline $\mathbf{9}$ & Bukit Larata & 3212 & 51 \\
\hline $\mathbf{1 2}$ & Capella Ubud & 7051 & 89 \\
\hline $\mathbf{1 3}$ & Wayag Shark Point & 3993 & 53 \\
\hline $\mathbf{1 4}$ & MelastiBeach & 3686 & 37 \\
\hline $\mathbf{1 5}$ & Semau Island & 2173 & 24 \\
\hline $\mathbf{1 8}$ & Pink Beach & 28578 & 396 \\
\hline $\mathbf{1 9}$ & Pulau Tomia & 4105 & 68 \\
\hline $\mathbf{2 5}$ & Mentawai & 15850 & 255 \\
\hline $\mathbf{2 6}$ & Pantai Mawi & 7507 & 77 \\
\hline $\mathbf{2 8}$ & Pulau Kei & 3909 & 73 \\
\hline
\end{tabular}




\begin{tabular}{|l|l|l|l|}
\hline $\mathbf{2 9}$ & Air Terjun Kapas Biru & 4110 & 64 \\
\hline $\mathbf{3 0}$ & Candi Borobudur & 6171 & 94 \\
\hline Total & & 135120 & 1655 \\
\hline Total keseluruhan & 879902 & 10954 \\
\hline
\end{tabular}

Sumber: (Data diolah peneliti, 2021)

Berdasarkan tabel 2, beberapa konten regram @indtravel terkategorisasi dengan atraksi wisata tertentu. Berikut pemaparannya:

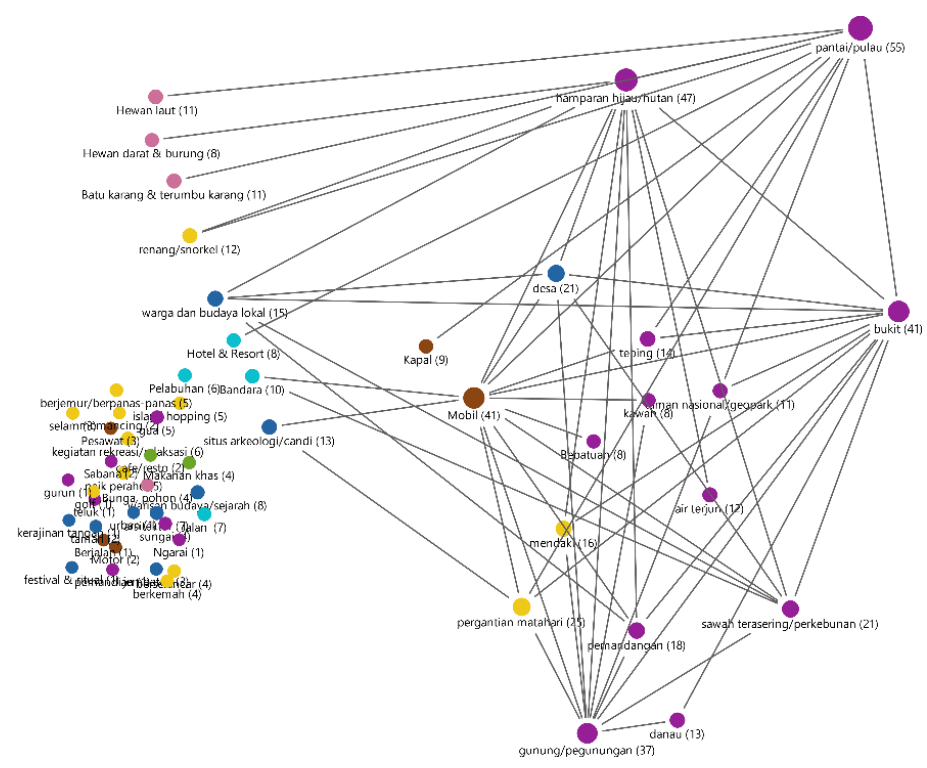

Gambar 4. Hasil pengkodean pada kategori atraksi Sumber: (Data diolah peneliti, 2021)

Dimensi konten unggahan dari @indtravel selama masa pembatasan wilayah terdiri atas beberapa dimensi yakni, atraksi wisata alam (300); atraksi wisata lain (72); flora dan fauna (34); makanan (6); transportasi (56); infrastruktur dan akomodasi (36); dan aktivitas wisata (88). Dimensi atraksi wisata alam menjadi mayoritas konten regram @indtravel yang ber-hashtag \#IndonesiaBucketList. Berdasarkan gambar 4, destinasi wisata Indonesia dalam konten regram @indtravel ber-hashtag \#IndonesiaBucketList memiliki berbagai kategorisasi dari atraksi wisata. Kategorisasi utama dalam dimensi atraksi wisata alam tertuju atas: pantai/pulau (55); hamparan 
hijau/hutan (47); Bukit (41); sawah terasering/perkebunan (21); dan Pemandangan (18). Sedangkan, kategori dalam dimensi lain yang berintensitas tinggi dalam konten regram @indtravel terdiri atas: desa (21), masyarakat dan budaya lokal (15) dalam atraksi wisata lain; mobil (41) dalam transportasi; Bandara (10) dalam Infrastruktur dan akomodasi; dan sunrise/sunset (25) dan mendaki (16) dalam aktivitas wisata.

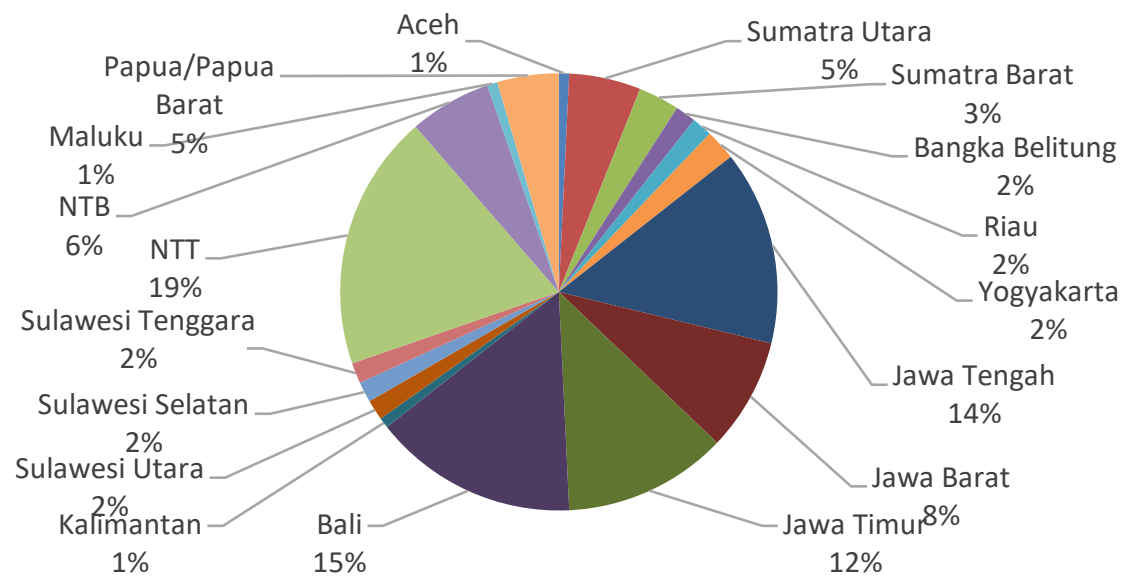

Gambar 5. Hasil pengkodean pada kategori Provinsi

Sumber: (Data diolah peneliti, 2021)

Berdasarkan gambar 5, mayoritas lokasi provinsi dalam konten regram @indtravel dengan hashtag \#IndonesiaBucketList selama pembatasan wilayah tertuju pada; NTT (19\%); Bali (15\%); Jawa Tengah (14\%); dan Jawa Timur (12\%). Jumlah like dalam konten di empat provinsi tersebut menunjukkan respon tinggi selama pembatasan wilayah. Dalam Periode tersebut, terdapat beberapa lokasi konten yang memiliki jumlah like tinggi seperti, Pink Beach (28578), Pantai Padar (25533), Kelingking Beach (22474), Dusun Butuh Kaliangkrik (15281), Waikelo Sawah Waterfall (14656), dan Cemoro Lawang (14344). Selain itu, dari gambar 6. terdapat kategorisasi elemen atraksi yang ada dalam konten regram @indtravel yang muncul di ketiga provinsi tersebut yakni: NTT (pantai/pulau, bukit, taman nasional/geopark, desa); Bali (hamparan hijau/hutan, dan pantai/pulau); Jawa Tengah (arkeologi/candi, hamparan hijau/hutan, gunung/pegunungan, pergantian matahari, mendaki); dan Jawa Timur (hamparan hijau/hutan, kawah, dan gunung/pegunungan). 


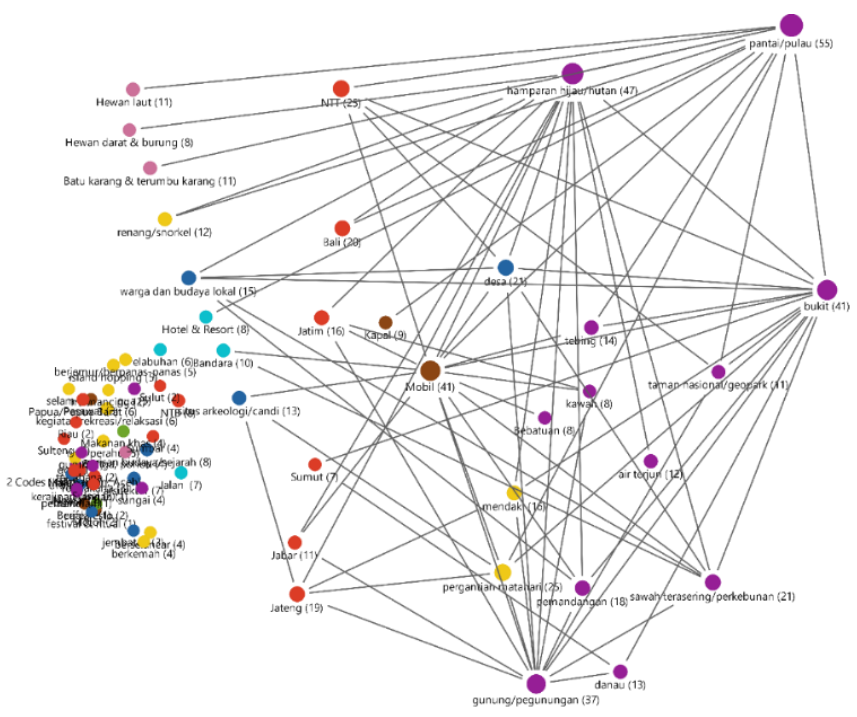

Gambar 6. Hasil pengkodean pada dimensi atraksi dan provinsi Sumber: (Data diolah peneliti, 2021)

Faktanya, pandemi Covid-19 terdampak negatif terhadap keempat provinsi dari mayoritas lokasi dari konten regram @indtravel. NTT memiliki penurunan di angka $80 \%$ kunjungan dan sangat berdampak negatif pada pemasukan daerah (Nugraha, 2021). Penyebabnya dikarenakan penundaan perjalanan oleh wisatawan sejak Agustus sampai Oktober 2020 akibat pandemi Covid-19 (Wilibardus, 2020). Terkait Bali, penutupan pariwisata sangat meluluhlantakan semua lini perekonomian di Bali (Paramita dan Putra, 2020). Meskipun Jawa Timur menduduki urutan kedua dengan kasus covid tertinggi di Indonesia, namun dari 969 DTW di seluruh kabupaten/kota di Jatim, sedikitnya ada 154 destinasi di 18 daerah yang sudah buka kembali (Jawapos.com, 2021). Secara tidak langsung, elemen alam menjadi mayoritas atraksi yang dipromosikan di konten regram @indtravel. Di samping itu, melalui hashtag \#IndonesiaBucketList, fokus branding destinasi wisata dari akun @indtravel tertuju pada penjaringan segemen pasar global. Selain itu, penggunaan bahasa Inggris dalam storytelling dari konten regram @indtravel menambah kekuatan optimalisasi strategi dari @indtravel. 


\section{Customer Engagement Marketing melalui Media Sosial}

@indtravel dapat dianggap tepat guna ketika melibatkan pengguna instagram dalam strategi branding destinasi wisata Indonesia. Upaya Customer Engagement Marketing yang dijalankan oleh @indtravel dari PSBB dimulai hingga PPKM Jawa-Bali pada akhir triwulan III tahun 2021 dijabarkan dalam siklus Customer Engagement itu sendiri. Tahapan awal dari @indtravel adalah melalui koneksi antar pengguna. Konten regram @indtravel yang menggunakan hashtag \#IndonesiaBucketList selama pembatasan wilayah menjadi upaya pembentukan pasar potensial. Hal ini dapat dianggap sebagai memo bagi follower maupun non-follower dari @indtravel untuk ikut berpartisipasi. Sehingga, pengguna Instagram lain terpancing untuk mengunggah berbagai konten ber-hashtag \#IndonesiaBucketList yang terkait destinasi wisata Indonesia.

Selanjutnya, konten regram @indtravel menunjukkan interaksi yang terhubung dengan konten pengguna yang di-regram. Gambar 5 merupakan contoh konten regram dari @indtravel yang berasal dari akun @elonroamer. Pada bulan september 2021 rasio respon like dan komentar di konten regram @indtravel cukup tinggi (1,89\%) dibandingkan dengan yang lain.
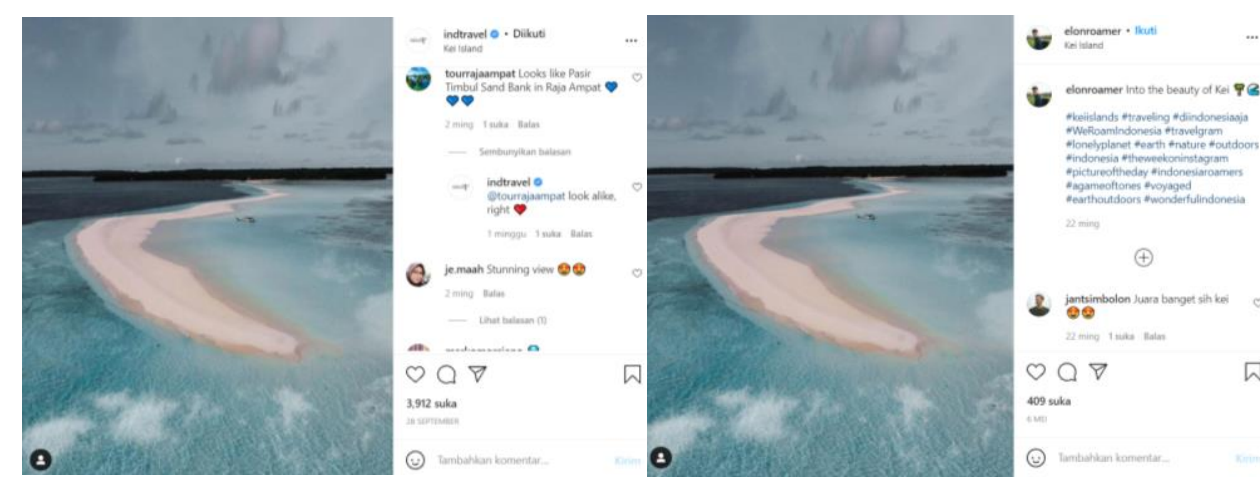

Gambar 5. contoh regram @indtravel dari akun lain Sumber: (Indtravel, 2021) 
Gambar 5. menunjukkan bahwa, @indtravel mengawali interaksi dengan meregram konten dari @elonroamer sebagai pemilik konten asli. Selanjutnya, hasil regram @indtravel direspon oleh follower maupun non-follower yang berkaitan dengan Pulau Kei sebagai destinasi utama yang disorot.

Kepuasan terkait konten regram @indtravel terlihat dari berbagai komentar positif dalam konten regram @indtravel. Setiap komentar yang dibalas dan terbalas kembali menunjukkan interaksi yang memperkuat proses customer engagement terhadap destinasi wisata yang ter-regram. Konten regram @indtravel berfokus pada pengalaman yang pernah dilakukan wisatawan. Hal ini diperjelas oleh caption @indtravel yang mengandung pengalaman dari destinasi wisata. Oleh karena itu, storytelling pada setiap konten regram @indtravel diupayakan menggugah minat calon wisatawan untuk berkunjung ke berbagai lokasi konten yang ter-regram. Beberapa konten regram memiliki intensitas komentar yang tinggi di @indtravel seperti, Bromo (109), Pantai Padar (135), Dusun Butuh Kaliangkrik (207), Pulo Cinta (185), Waikelo Sawah Waterfall (242), dan Pink Beach (396). Konten unggahan dapat berdampak pada online engagement yang diwakili oleh like dan komentar (Luarn dkk., 2015). Semakin banyak jumlah like dan komentar maka semakin besar respon yang muncul dari konsumen (Santoso dkk., 2017). Dengan kata lain, keanekaragaman dan intensitas respon dari sebuah konten regram akan ikut menghubungkan pengguna instagram dengan destinasi wisata yang di-regram @indtravel.

Proses customer engagement oleh @ind travel menghadirkan ingatan bagi follower yang pernah mengunjungi salah satu destinasi wisata. Ingatan dari pengalaman menghadirkan emosi negatif maupun positif atas destinasi wisata. Selain itu, hashtag \#IndonesiaBucketList mampu menjaring fokus dari konten regram @indtravel. Intensitas komentar yang muncul menunjukkan berbagai pengalaman dari follower yang pernah mendatangi lokasi dari konten regram @indtravel. Oleh karena itu, terdapat komentar kurang positif yang ikut muncul di kolom komentar. Dimana sifatnya justru dapat dirunut sebagai saran yang bermakna disfemisme. 
“Kemacetannya tolong dikondisikan”(@prardi22, 2021).

"why using photoshopped image? Padar island is naturally beautiful. no need to be photoshopped"(@una.domu, 2021)

“They will destroy the ecosystems" (@wahyutamanbunga, 2021).

“Hutan diganti dengan rumah dan perkebunan (2) “(@fakhrulroziiii, 2021).

"what picture doesn't show you is all teh plastic, flip flops and nappies and other trashed washed up in beach" (@lee_tuned, 2021).

“Taunya, waktu ke sini airnya coklat (-)"(zeniqorotu, 2021).

Salah satu fungsi disfemisme adalah untuk menghujat atau mengkritik (Kurniawati, 2011). Oleh karena itu, ingatan seseorang akan destinasi akan menghasilkan persepsi yang berbeda, baik positif maupun negatif. Selanjutnya, muncul beberapa komentar yang menunjukkan komitmen dari follower dari @indtravel.

"I am glad before covid, I managed to visit this amazing place $(-)$ "(expeditioustraveler, 2021).

"Hati2, foto diedit. Saran: kalo mau liat pemandangan nepal van java, liat dari atas, bukan kunjungin ke desanya. Kalo mau ngunjungin ke desanya silahkan, tp tdk akn mndpatkan pemandangan kyak gini. But trust me, it worth to be visited!"(christinanugrahaeni, 2021).

"I've been here, teh best sih ini tempat. Wajib kesini saat ke Sumba"(mtrsr, 2021).

"This place is unbelievably pretty $\theta \theta \theta$ 을 loved Indonesia when we visited last year." (khanadians, 2021).

"loved Labuan Bajo! Look forward to going back but with my family this time! I'm sure they'll love it just as much" (cindieloo, 2021). 
Komitmen yang dimaksud adalah kedekatan hubungan dengan destinasi. Komentar di salah satu konten regram @indtravel dapat disampaikan secara positif. Salah satunya, cindieloo (2021) menunjukkan rasa emosionalitas positif dan kepercayaan terhadap sebuah destinasi. Dimana, komentar positif memungkinkan adanya peningkatan minat berkunjung melalui konten regram @indtravel.

Tahap selanjutnya, advokasi dalam siklus customer engagement berusaha meningkatkan dukungan atas branding destinasi selama masa krisis. Kampanye media sosial melalui hashtag \#IndonesiaBucketList memancing berbagai unggahan konten dari akun Instagram lain.

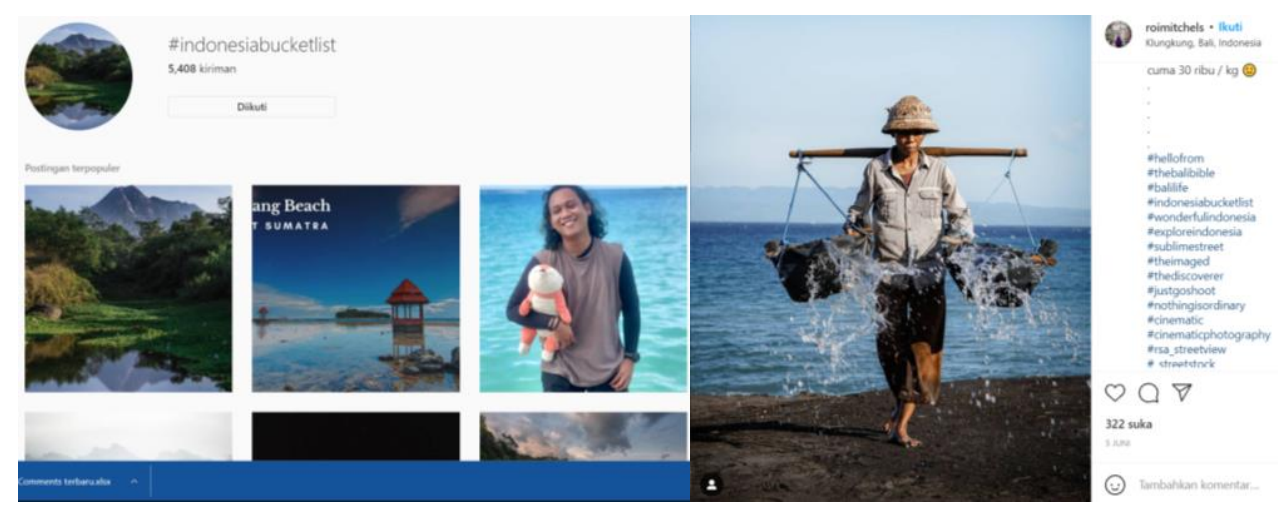

Gambar 6. \#IndonesiaBucketList di berbagai konten akun Instagram lain Sumber: (Indtravel, 2021)

Gambar 6. menjelaskan bahwa, sebanyak 5408 akun mengikuti kampanye online ber-hashtag \#IndonesiaBucketList. Ketergantungan atas pemanfaatan media sosial berkontribusi pada atraksi wisata. Terpangkasnya biaya promosi dalam jumlah besar dikarenakan electronic WOM (Živković, dkk., 2014). Dalam hal ini, Hashtag \#IndonesiaBucketList mengkerucutkan branding destinasi wisata secara konstruktif.

Banyaknya konten selain dari akun @indtravel yang ber-hashtag \#IndonesiaBucketList menunjukkan adanya respon baik. Adanya keterlibatan akun instagram lain merupakan bagian dari proses optimalisasi customer engagement marketing. Tahapan ini menunjukkan apresiasi pengguna melalui kesenangan berbagi 
konten berisi destinasi wisata Indonesia, baik follower atau non-follower dari @indtravel. Prespektif positif dari kampanye \#IndonesiaBucketList dalam konten regram @indtravel maupun akun lainnya akan menunjukkan loyalitas yang ditunjukkan oleh model interaksi dalam konten. Selain itu, customer engagement marketing melalui peran konten regram akun @indtravel memunculkan efisiensi biaya dari destinasi. Segmen pasar psikosentris di era 4.0 menjadi pertimbangan dalam penyusunan strategi pemasaran yang lebih murah dan efisien melalui euforia media sosial (Hanggraito \& Sanjiwani, 2020). Di sisi lain, atraksi alam destinasi wisata Indonesia ditonjolkan dalam konten regram @indtravel. Hal ini dapat ditilik sebagai salah satu upaya pemerintah dalam menstabilkan minat berwisata dari wisatawan domestik maupun mancanegara di masa krisis. Analisis terhadap upaya customer engagement marketing dari @indtravel menunjukkan bahwa, hashtag \#IndonesiaBucketList menjadi materi penting dalam proses branding destinasi wisata. Hashtag \#IndonesiaBucketList yang dimulai sejak bulan mei 2020 diungkap sebagai upaya penguatan mental wisatawan secara global. Optimalisaisi media sosial dapat dianggap sebagai upaya pemerintah dalam menjaga keberlanjutan lingkungan destinasi wisata selama pemulihan wisata.

\section{Kesimpulan}

Jangkauan internet yang semakin luas mendukung@indtravel dalam meningkatkan minat berkunjung wisatawan global ke destinasi wisata Indonesia. Oleh karena itu, @indtravel berpeluang besar dalam meningkatkan branding destinasi wisata di masa pandemi Covid-19. Dalam penelitian ini mayoritas konten regram @indtravel tertuju pada atraksi alam sebagai fokus branding destinasi wisata di Indonesia selama masa krisis. Selain itu, mayoritas konten regram @indtravel selama pembatasan wilayah tertuju pada provinsi NTT, Bali, Jawa Tengah, dan Jawa Timur. Hasil analisis siklus customer engagement menjelaskan bahwa, peran promosi dari @indtravel di masa krisis dapat membantu upaya customer engagement marketing dari 
destinasi wisata Indonesia. Penelitian ini terbatas pada konten regram dari @indtravel dengan hashtag \#IndonesiaBucketList yang diunggah selama masa PSBB hingga PPKM Jawa-Bali di akhir triwulan III 2021. Hashtag \#IndonesiaBucketList dapat memaksimalkan upaya customer engagement marketing di masa krisis sehingga promosi destinasi wisata masih berjalan. Penelitian ini memberikan wawasan penting terkait customer engagement marketing melalui perspektif penelitian kualitatif yang didasarkan atas model konten regram dari @indtravel. Penelitian ini menjelaskan upaya branding destinasi wisata Indonesia di masa krisis dapat dilakukan oleh siapapun selama mengoptimalkan berbagai atribut media sosial. Penelitian selanjutnya diharapkan menggunakan variabel berbeda dalam mengungkap model customer engagement marketing melalui media sosial di masa krisis.

\section{Daftar Pustaka}

Benedek, I. (2018). Instagram as a Tool for Destination Branding - Case Study on the Major Cities of Romania. Journal of Media Research, 11(2 (31)), 43-53. https://doi.org/10.24193/jmr.31.3

Cai, L. A. (2002). Cooperative branding for rural destinations. Annals of Tourism Research, 29(3), 720-742. https://doi.org/10.1016/S0160-7383(01)00080-9

Chloridiany, A. (2021). Social Media Marketing Strategy of Indonesian Tourism in The Time of Pandemic. E-Journal of Tourism, 8(1), 1. https://doi.org/10.24922/eot.v8i1.71445

Glaesser, D. (2006). Crisis Management in the Tourism Industry (2nd ed.). Routledge.

Hanan, H., \& Putit, N. (2013). Express marketing of tourism destinations using Instagram in social media networking. Hospitality and Tourism, 471-474. https://doi.org/10.1201/b16064-93

Hanggraito, A. A., \& Sanjiwani, N. M. G. (2020). Tren Segmentasi Pasar dan Perilaku Wisatawan Taman Bunga Amaryllis di Era 4.0. Journal of Tourism and Creativity, 4(1), 43. https://doi.org/10.19184/jtc.v4i1.14476

Jatmiko, L. D. (2020). APJII: 196,7Juta Warga Indonesia Sudah Melek Internet. https://m.bisnis.com/amp/read/2020\%0A1110/101/1315765/apjii-1967jutawarga-\%0Aindonesia-sudah-melekinternet 
Jawapos.com. (2021). 154 Destinasi Wisata di Jawa Timur Mulai Reopening. https://www.jawapos.com/surabaya/03/08/2020/154-destinasi-wisata-di-jawatimur-mulai-reopening/.

Josef, P., Strannegård, L., \& Jonsson, S. (2014). Organizations and the Media: Organizing in a Mediatized World. Routledge.

Kaplan, A. M., \& Haenlein, M. (2010). Users of the world, unite! The challenges and opportunities of Social Media. Business Horizons, 53(1), 59-68. https://doi.org/10.1016/j.bushor.2009.09.003

Kemp, S. (2019). Digital 2019: Global Internet Use Accelerates. https://wearesocial.com/blog/2019/01/digital-2019-global-internet-useaccelerates

Kompaspedia. (2021). Kebijakan Covid-19 dari PSBB hingga PPKM Empat Level. https://kompaspedia.kompas.id/baca/infografik/kronologi/kebijakan-covid19-dari-psbb-hingga-ppkm-empat-level. diakses tanggal 16 September 2021 pukul 20.28 WIB.

Kotler, P., Amstrong, G., \& Opresnik, M. O. (2018). Principles of marketing (17th ed.). Pearson.

Krippendorff, K. (2004). Content Analysis : An Introduction (M. H. Seawell (ed.); 2nd ed.). Sage Publications. https://doi.org/10.1103/PhysRevB.31.3460

Kurniawati, H. (2011). Eufisme dan Disfemisme dalam Spigel Online. LITERA, 10(1), 51-63. https://doi.org/10.21831/1tr.v10i1.1172

Kuščer, K., Eichelberger, S., \& Peters, M. (2021). Tourism organizations' responses to the COVID-19 pandemic: an investigation of the lockdown period. Current Issues in Tourism, 0(0), 1-14. https://doi.org/10.1080/13683500.2021.1928010

Kusuma, N. A. P., Suprihanto, J., \& Ahimsa-Putra, H. S. (2020). Membangun Promosi Pariwisata Melalui Regram Studi Akun Instagram @indtravel. Jurnal Kawistara, 10, 378-390. https://doi.org/https://doi.org/ 10.22146/kawistara. 59146

Luarn, P., Lin, Y. F., \& Chiu, Y. P. (2015). Influence of Facebook brand-page posts on online engagement. Online Information Review, 39(4), 505-519. https://doi.org/10.1108/OIR-01-2015-0029

Mustofa. (2019). Peran Hashtag (\#) Dalam Media Sosial Sebagai Upaya Branding Pustakawan. Libraria, 7(1), 19-38.

Nafees, L., \& Harish, R. (2010). Brand architecture in tourism branding: The way forward for India. Journal of Indian Business Research, 2(3), 153-165. https://doi.org/10.1108/17554191011069442 
Nassaji, H. (2015). Qualitative and descriptive research: Data type versus data analysis. Language Teaching Research 2015, Vol. 19(2) 129- 132 DOI: $10.1177 / 1362168815572747$.

Novelli, M., Morgan, N., \& Nibigira, C. (2012). Tourism in a post-conflict situation of fragility. Annals of Tourism Research, 39(3), 1446-1469. https://doi.org/10.1016/j.annals.2012.03.003

Nugraha, Y. E. (2021). Dampak Pandemi Covid 19 Pada Unit Usaha Pariwisata Di Kawasan Pesisir Kota Kupang. Jurnal Industri Pariwisata Vol 3, No. 2, 2021. eISSN : 2620-9322

Paramita, I. B. G., \& Putra, I. G. G. P. A. (2020). New Normal Bagi Pariwisata Bali Di Masa Pandemi Covid 19. Pariwisata Budaya: Jurnal Ilmiah Pariwisata Agama dan Budaya EISSN 2614-5340.

Permatasari, N., \& Trijayanto, D. (2017). Motif Eksistensi melalui Penggunaan Hashtag (\#OOTD) di Media Sosial Instagram. PROMEDIA, Volume Ke- 3, No. 2, 2017, Permatasari, dkk, Motif Eksistensi, 252-273.

Santoso, A., Baihaqi, I., \& Persada, S. (2017). Pengaruh Konten Post Instagram Terhadap Online Engagement: Studi Kasus pada Lima Merek Pakaian Wanita. Jurnal Sains Dan Seni ITS, 6(1), 50-54.

Shao, Y., Hu, Z., Luo, M., Huo, T., \& Zhao, Q. (2021). What is the policy focus for tourism recovery after the outbreak of COVID-19? A co-word analysis. Current Issues in Tourism, 24(7), 899-904. https://doi.org/10.1080/13683500.2020.1806798

So, K. K. F., King, C., Sparks, B. A., \& Wang, Y. (2014). The Role of Customer Engagement in Building Consumer Loyalty to Tourism Brands. Journal of Travel Research, 0047287514541008.

Sigala, M. (2020). Tourism and COVID-19: Impacts and implications for advancing and resetting industry and research. Journal of Business Research, 117, 312-321. https://doi.org/10.1016/j.jbusres.2020.06.015

Suryana. (2010). Metodologi Penelitian: Metodologi Penelitian Model Prakatis Penelitian Kuantitatif dan Kualitatif. In Universitas Pendidikan Indonesia. https://doi.org/10.1007/s13398-014-0173-7.2

Wearesocial. (2019). Berapa Pengguna Media Sosial Indonesia? https://databoks.katadata.co.id/datapublish/2019/02/08/berapa-penggunamedia-sosial-indonesia

Wilibardus, D. (2020). Dampak Pandemi Covid-19 untuk Pelaku Pariwisata di Sikka. https://www.liputan6.com/regional/read/4349298/dampak-pandemi-covid-19untuk-pelaku-pariwisata-di-sikka 
Živković, R., Brdar, I., \& Gajic,J. (2014). The Impact of Social Media on Tourism. Conference Paper of E-Business in Tourism and Hospitality Industry (SINTEZA).

\section{Profil Penulis}

Ahmadintya Anggit Hanggraito adalah dosen di Prodi Manajemen Bisnis Pariwisata Politeknik Negeri Banyuwangi. Dia menyelesaikan studi S1 Administrasi Bisnis Universitas Brawijaya Malang pada tahun 2012, S2 Kajian Pariwisata Universitas Gadjah Mada Yogyakarta pada tahun 2019.

Setya Mukti Mahanani adalah seorang mahasiswa yang saat ini sedang menyelesaikan S2 Kajian Pariwisata Universitas Gadjah Mada Yogyakarta. Dia menyelesaikan studi S1 Sastra Inggris Universitas Airlangga Surabaya pada tahun 2017.

Noer Ayufika Nulul adalah seorang mahasiswa yang saat ini sedang menyelesaikan S2 Kajian Pariwisata Universitas Gadjah Mada Yogyakarta. Dia menyelesaikan studi S1 Ilmu Komunikasi Universitas Islam Indonesia Yogyakarta pada tahun 2017. 